www.jmscr.igmpublication.org

Impact Factor (SJIF): 6.379

Index Copernicus Value: 71.58

ISSN (e)-2347-176x ISSN (p) 2455-0450

crossref DOI:_https://dx.doi.org/10.18535/jmscr/v6i2.11

Journal Of Medical Science And Clinical Research

\title{
Impact of Intensified Campaign on Immunization of under 16 Children During Outbreak of Diphtheria in Manjeri Municipality from June 2016 - October 2016
}

\author{
Authors \\ Dr Hakkim N ${ }^{1}$, Dr Ajith Kumar V T ${ }^{2}$, Dr Mohandas Nair ${ }^{3}$, Dr Sajini ${ }^{4}$ \\ ${ }^{1}$ Consultant, General Hospital, Manjeri, Kerala \\ ${ }^{2}$ MBBS, MD (Paediatrics), DNB, DCH, Professor and Head, Department of Pediatrics, Govt. Medical College, \\ Manjeri, Kerala \\ ${ }^{3}$ MD DNB, Additional Professor, Department of Pediatrics, Govt. Medical College Kozhikode, Kerala \\ ${ }^{4}$ Assistant Surgeon, Govt. Hospital Manjeri, Kerala \\ Corresponding Author \\ Dr Ajith Kumar V T \\ MBBS, MD (Paediatrics), DCH, Professor and Head, Dept of Pediatrics, Govt. Medical College, Manjeri, Kerala

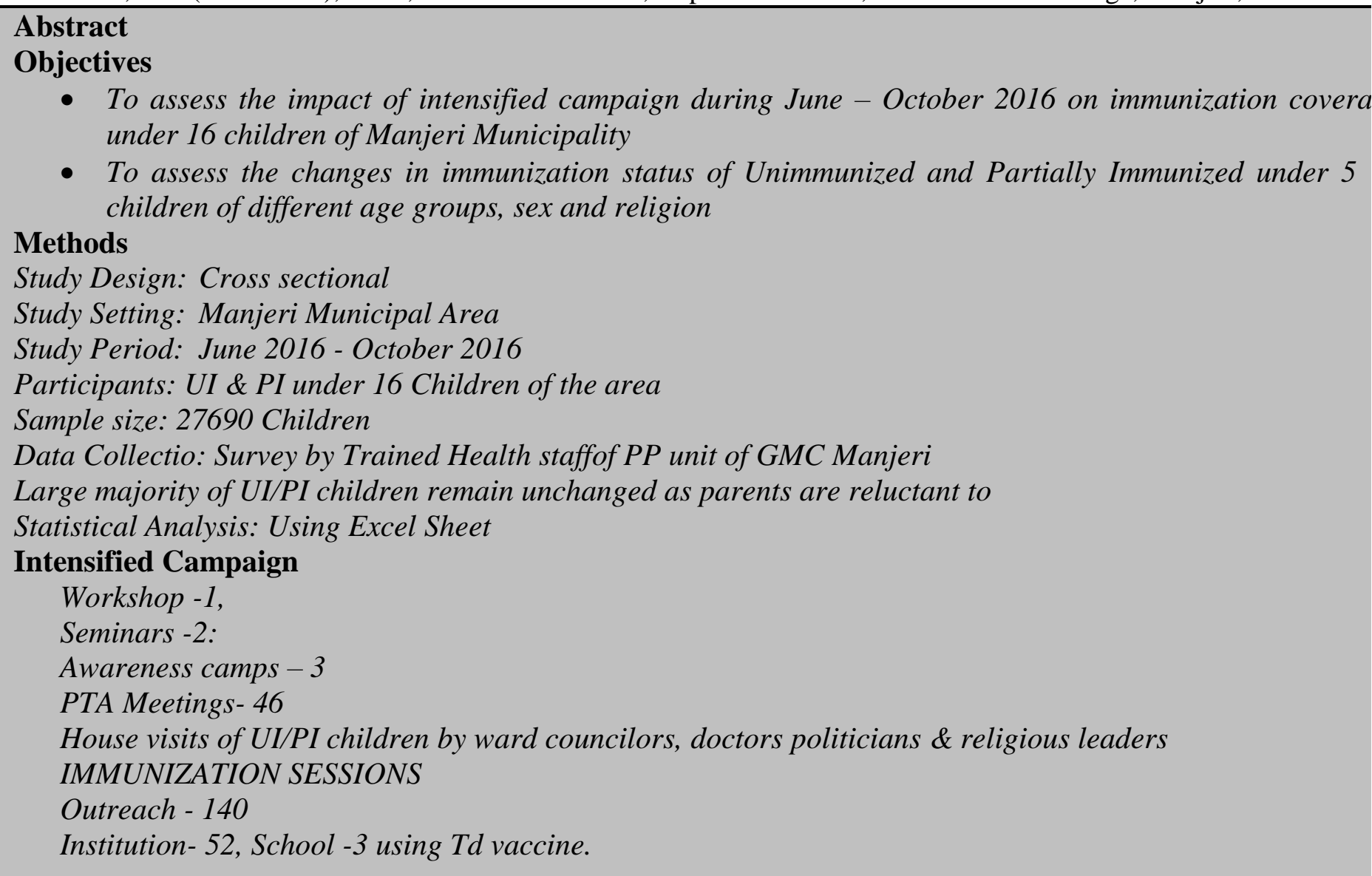



Results
I. Immunization coverage as on 30-06-2016
- Under 5 children (8341):80.02\% [0.19\%UI \& 18.89\%PI]
- Under 16 children (27690):76.05\% [2.77\%UI \& 21.8\%PI]
II. After the intensified immunization campaign changes observed are
- PI Children: 0-5 years:9\%became fully immunized0-16 years: $18.07 \%$ became FI
- UI Children: 0- 5 years:3.77\%became PIO-16 years: 19\%became PI
III. Older children (7-16) are getting benefitted
With school immunizations schedules with 3 sessions $\mathbf{3 2 . 8 \%}$ UI got Td vaccination.
IV. On comparing the immunization status of
0-5 children at two different points of time on 30-06-2016 to and 31-10-2016 results are as follows:

Keywords: diphtheria; immunization; outbreak.

\section{Background}

Diphtheria an acute infectious disease caused by Coryne bacterium diphtheria remain a matter of considerable concern in Malappuram district of Kerala especially after the resurgence of microbiologically confirmed diphtheria, clustering of cases and two deaths occurred during the month of June-July of 2016. Health authorities had constituted outbreak control teams and intensified the immunization campaign. Despite a similar episode in 2015 Sept-October 2015 with two death due to diphtheria, intensified campaigns during the last months of 2015, the resurgence of diphtheria is quite threatening.

In Manjeri municipality with over one lakh population two cases, a $12 \mathrm{yr}$ old girl and $39 \mathrm{yr}$ old male were diagnosed to have Pharyngeal diphtheria, in the month of July 2016 and September 2016 respectively. The earlier documented case was in 2013 in 14 yr old girl, with zero percentage mortality.

With the onset of the current epidemic (Cases were reported from our district) introspection was done to improve the immunization coverage of our area, following which an intensified campaign to strengthen the immunization status of under five children sand a qualitative study was initiated by interviewing people across the municipality to understand the variables.

In the pre vaccination era diphtheria was a leading cause of childhood mortality. After the introduction of universal immunization programme and wide spread campaigns the incidence and mortality of diphtheria had reduced considerably to almost nil in our state.

But during the last decade we had come across a few cases in the district, and documented cases had shown more occurrences in adolescent age group compared to the younger population, in which our National programme concentrate.

Earlier studies had shown that, following primary vaccination ant diphtheria antibodies wane in the absence of boosting either by natural exposure or through administration of booster vaccination. With this current data of reported cases and more detailed study is needed to judiciously interpret the available data about immunization coverage and formulate newer strategies in our current immunization policy. Availability of age specific and region specific data about immunization coverage is of paramount importance in the implementation of newer strategies.

\section{Aim of the Study}

To assess the immunization coverage of under 5 /under 16 children in Manjeri municipality and to assess, whether interventions of intensified campaigning during the epidemic of diphtheria, have altered immunization coverage and practices of parents / children of Manjeri municipality.

\section{Study type}

Retrospective descriptive study

Study period June2016 to October 2016

\section{Definition}

The following definitions were used 


\section{Infant}

\section{Fully immunized}

An infant who has received BCG,3 doses of Pentavalent, 3 doses of OPV and measles vaccines before $1 \mathrm{yr}$ of age.* 1

\section{Under 7 yr}

\section{Fully immunized}

BCG,3 primary and 2 booster doses of DPT , OPV, 2 measles before 7 yrs.

\section{7-16 yr}

\section{Fully immunized}

BCG,3 primary and 2 booster doses of DPT , OPV, 2 measles before $7 \mathrm{yrs}$ and 1 dose of TT/Td at 10 and 16 yrs.

\section{Partially immunized}

If some dose given but immunization not complete

\section{Unimmunized}

Not received any of the above vaccines.

Age was confirmed by birth certificate or immunization card or when it was not available by asking the mother. The child was considered as immunized or not, based on the immunization card. For those without an immunization card, information from the mother or a family member stating that the child has been immunized was considered.

\section{Materials and Methods}

Immunization coverage evaluation was done using the earlier collected data from the PP unit of General Hospital, Manjeri and survey carried out by trained health care personals of PP unit during the month of June 2016.

An intensified campaigns for reaching out the Unimmunized / Partially immunized children was carried out with different programmes like workshops, seminars, awareness camps, mass media awareness programmes through Television, FM radio, newspaper, publication of brochures, Posters, awareness generation campaigns through PTA meetings held exclusively for this purpose, House visits by elected ward counselors, politicians, religious leaders, school teachers
ASHA, Anganwadi workers, social workers, doctors and trained health staff.

Mass media immunization drive was combined with community counseling to enhance the utilization of immunization services. Communities were targeted to remove the fear of vaccines in the decision makers like fathers, mother in-laws in addition to mothers and antivaccine propaganda were countered well. Healthcare workers were trained to counsel the caretaker and persuaded to avail immunization services.

\section{Report of activities organized}

A. Sensitization meetings

1. LSGD: For Majeri municipal counselors at Municipal office conference hall. Pediatrician from GMCH and Asst. Prof. from community medicine department attended the meeting, explained about the current epidemic of diphtheria, vaccine preventable diseases covered under UIP, vaccination coverage status of children of Manjeri municipality, discussed about the malicious propaganda against vaccines. Municipal chairperson, vice chairman and all counselors (about 50), field health staff of municipality attended. (Date June .....'16)

2. JPHNs, ASHA, JHI, Field Supervisors (OP Hall GMC Hospital date ......... June '16) Training given to health staff regarding data collection, to update the line list of UI/PI children sensitized about diphtheria and its symptoms, so that cases can be referred early. Deputy Supdt, Pediatrician, MO in charge of immunization handled the sessions.

3. Anganwadi workers: at Urban bank Auditorium : Pediatrician, JHI from PP unit attended the meeting conducted awareness lass on diphtheria, VPDs, discussed strategies to reach and fully immunize the UI/PI children Manjeri municipality. More than 100 AWTs, ICDS supervisors and CDPO $\mathrm{s}$ were attended........ (Date: July .......'16). 
B. Mass Media Campaigns

1. Published an article in Malayalam daily's (written by HOD Pediatrics) highlighted about the current epidemic of diphtheria. And the necessity of urgent and serious community interventions to fill the gap in the immunization coverage and given an call to ignore the irrational, un scientific arguments against vaccines. (Date Suprabhatham 27/06/2016, Chandrika27 /06/2016, Malayala Manorama July 2016, Tejas July 2016.)

2. Debates in visual Media: 1. On Sahya channel HOD Pediatrics, HOD community medicine, Pediatrician, Deputy DMO participated and countered the unscientific arguments of antivaccine campaigners. June 2016, 2. On Media One channer (HOD pediatrics participated) given scientific explanation and rational of childhood immunization 3. On Kerala vision: Pediatrician from dept of pediatrics participated discussion / telephone in programme, 4. On FM Radio Manjeri Pediatician from dept of Paeds. Participated.

3. IEC Materials Published: 10000 copies of brochures, 500 copies of collash posters on diphtheria, national immunization schedule and catch up immunization distributed in the municipality.

C. Street Plays: Street play of 25 minutes duration played by professional artists played in 9 different pockets of municipality. Message was vaccination and its importance to create VPD free world. 50 to 200 people viewed in each pockets.

D. Workshops/Seminar: To influence the targeted population the role of community leaders were recognized, to utilize their services organized one day workshop (25 July 16) 50 municipal ward counselors, social workers, one teacher each from 51 schools in the municipality, political, cultural organization leaders, IAP, IMA, KGMOA representatives, doctors from other systems of medicine Homeo, Ayurveda ICDS, Kudumbashree workers, attended the workshop. HOD Pediatrics, HOD community medicine; senior pediatricians from the GMCH handled different topics regarding vaccination. Topics discussed: VPD's covered under UIP, national
Immunization schedule, Catch up immunization criticism /Facts on vaccines, Safety and efficacy of vaccines, action plan for Manjeri municipality were discussed.) Video shows and power point presentations used. Registration more than 250

EVENING SEMINAR: In PTA meetings and House visits, Majority of the audients were parent participation conducted an evening seminar a community hall, Cholakkal, Supdt. of GMCH, Pediatricians, handled topics and discussions, different religious group leaders, political party workers, cultural organization leaders participated. Registration 100. Video shows arranged.

E. PTA Meetings: Manjeri Municipality has 51 schools. (in June July) with the support of Education Dept, PTA meetings were held exclusively for conducting awareness programme on immunization in 46 schools. In each school 45 60 minutes sessions were held. Sessions were handled by pediatricians, lecturer, Asst. prof from community medicine dept. topics VPD's and vaccination, NIS, catch up immunization, safety, efficacy Parents doubts on safety, efficacy AEFI issues were discussed and cleared. 50 to 500 parents were attended the sessions. Video shows, Power point presentation used wherever facility available.

Awareness class for focused groups: conducted an awareness class on UIP and VPD's for 1 hour for Auto rickshaw drivers of Manjeri municipality. Attendance above 350.

Formed Manjeri people health forum (Manjeri Janakeeyaarogyasamithy) this is a collectiveness of municipal level leaders of religious cultural, political organizations.

House visits of UI/PI children: A term of ward counsellors, Pediatritian, Medical officers, JPHN, AWT, ASHA, Social workers visited all the houses of UI/PI children in July/ August/Sept/ October. During the visits doctors /health staff communicated / counseled the parents of target children. On an average 25-30 mts spent in each house. Tried to improve their knowledge on vaccination, clear misconceptions about vaccines, and fear of AEFI s. 
Immunization sessions: on an average 35 outreach sessions in different pockets of the municipal area, 13 institution sessions were held monthly (July, August, September, October). School level immunization in 3 schools are also conducted. House visits by doctors were done on the day/previous day of immunization.

\section{Total immunization session.}

- Outreach - 140

- Institution- 52

- School -3

- Since this intensified immunization campaign was intended to contaign the present diphtheria out break we used $\mathrm{Td}$ vaccine instead of TT for older children (7-16 years).

\section{Results}

Immunization status before and after intensive campaigning

\begin{tabular}{|l|c|c|c|c|c|c|c|}
\hline \multirow{2}{*}{ Age Group } & \multicolumn{3}{|c|}{ Unimmunized } & \multicolumn{3}{c|}{ Partially Immunized } & Total No. \\
\cline { 2 - 7 } & Total & Converted & Change \% & Total & Converted & Change \% & Children \\
\hline $0-5$ & 159 & 6 & 3.77 & 1508 & 137 & 9 & 8341 \\
\hline $5-7$ & 103 & 2 & 1.94 & 637 & 130 & 20.4 & 3791 \\
\hline $7-16$ & 506 & 166 & 32.8 & 3720 & 369 & 9.9 & 15558 \\
\hline Total & 768 & 184 & 23.9 & 5865 & 906 & 15.4 & 27690 \\
\hline
\end{tabular}

\section{Immunization coverage as on 30-06-2016}

Under 5 children (8341):

$80.02 \%$ [0.19\%Unimmunized (UI)

$18.89 \%$ Partially Immunized (PI)

$\begin{array}{lllll}\text { Under } & 16 & \text { children (27690) } & 76.05 \% & {[2.77 \%}\end{array}$

Unimmunized \& 21.8\%Partially Immunized

After the intensified immunization campaign

changes observed are

Unimmunized children
Partially Immunized Children:

0-5 years: $9 \%$ became fully immunized

0-16 years : $18.07 \%$ became fully immunized (FI)

Unimmunized Children

0- 5 years: $3.77 \%$ became PI

0-16 years: $19 \%$ became PI

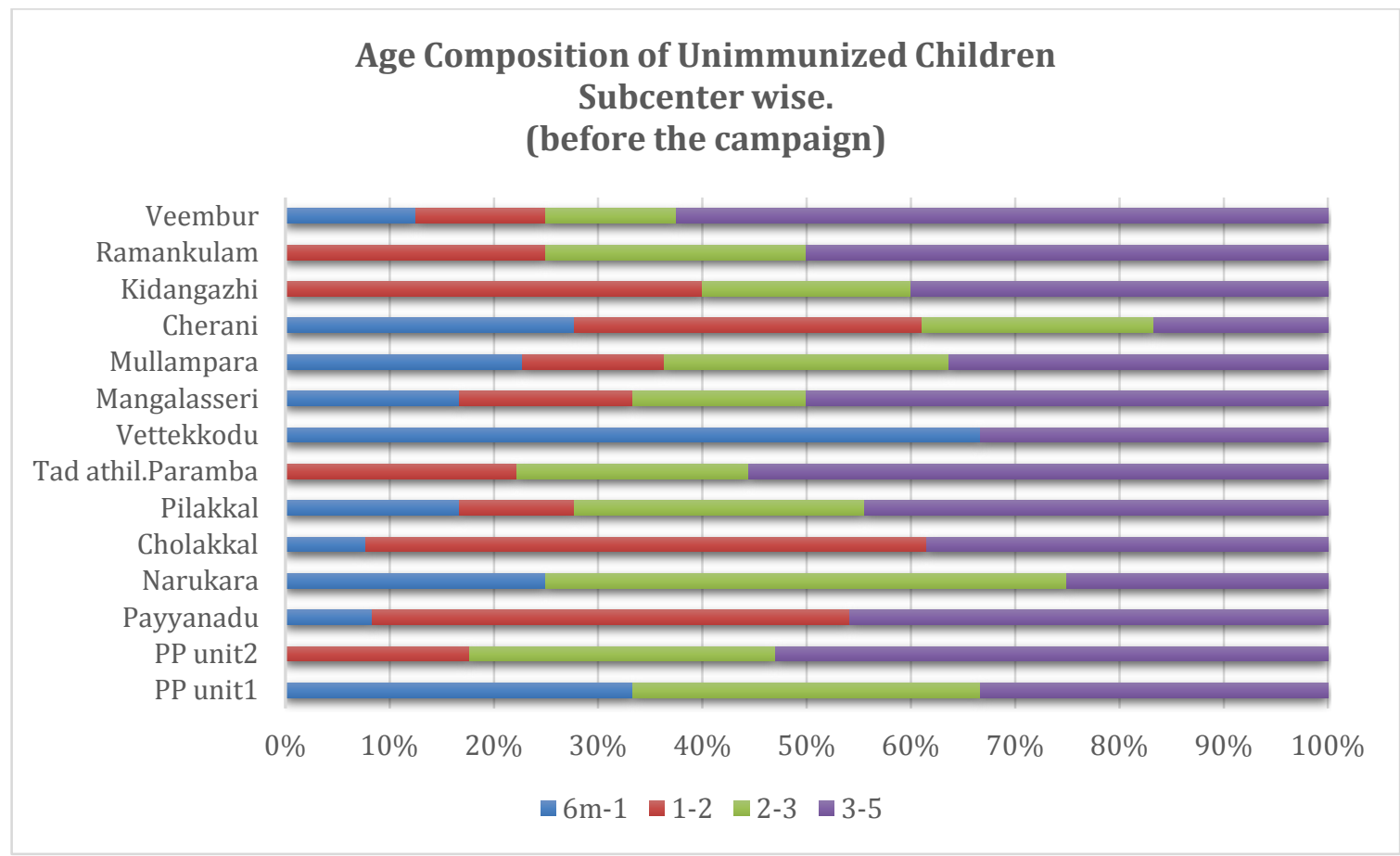


Immunization status of unimmunized children below 5 years

\begin{tabular}{|l|c|c|}
\hline Age UI & On 30-06-2016 & On 31-10-2016 \\
\hline 6mo-1 year & 22 & 22 \\
\hline 1-2 year & 41 & 38 \\
\hline 2-3 year & 30 & 36 \\
\hline 3-5 years & 66 & 67 \\
\hline
\end{tabular}

unimmunized children before and after the campaign in Manjeri Municipality

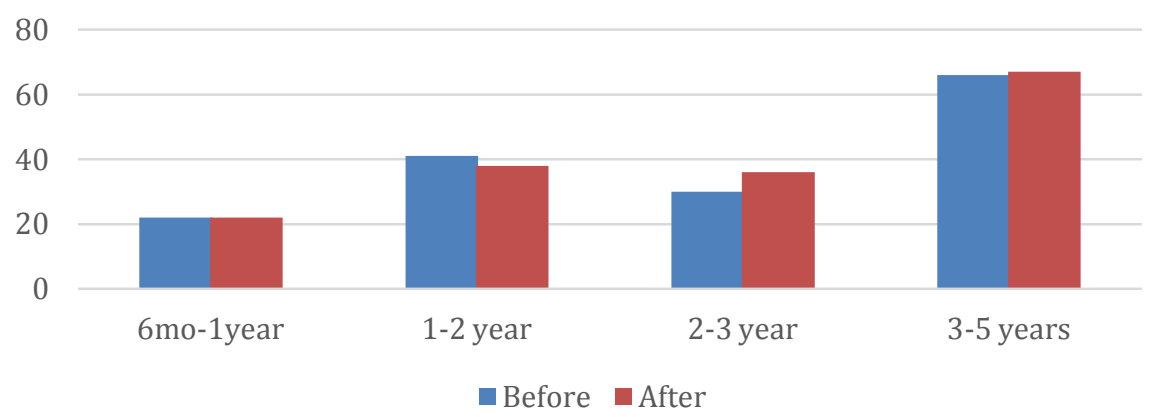

There was no change in the immunization status of unimmunized children with intensive campaign Comparing the immunization status in unimmunized males and female children less than 5 years

Partially immunized

\begin{tabular}{|l|c|c|}
\hline UI female & On 30-06-2016 & On 31-10-2016 \\
\hline 6mo-1year & 6 & 6 \\
\hline 1-2 year & 20 & 18 \\
\hline 2-3 year & 12 & 14 \\
\hline 3-5 years & 29 & 29 \\
\hline
\end{tabular}

\begin{tabular}{|l|c|c|}
\hline Age PI & On 30-06-2016 & On 31-10-2016 \\
\hline 6mo-1 year & 161 & 152 \\
\hline 1-2 year & 392 & 364 \\
\hline 2-3 year & 340 & 328 \\
\hline 3-5 years & 615 & 560 \\
\hline
\end{tabular}

Immunization status of PI based on Gender

No of partially immunized female children before and after the campaign

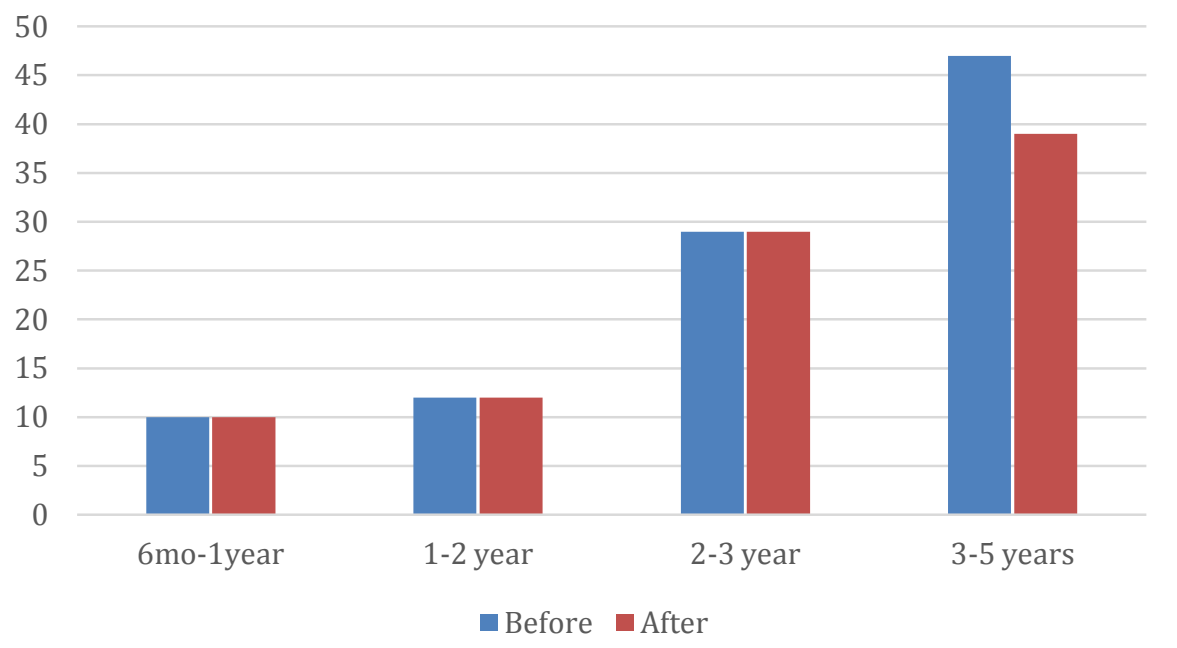




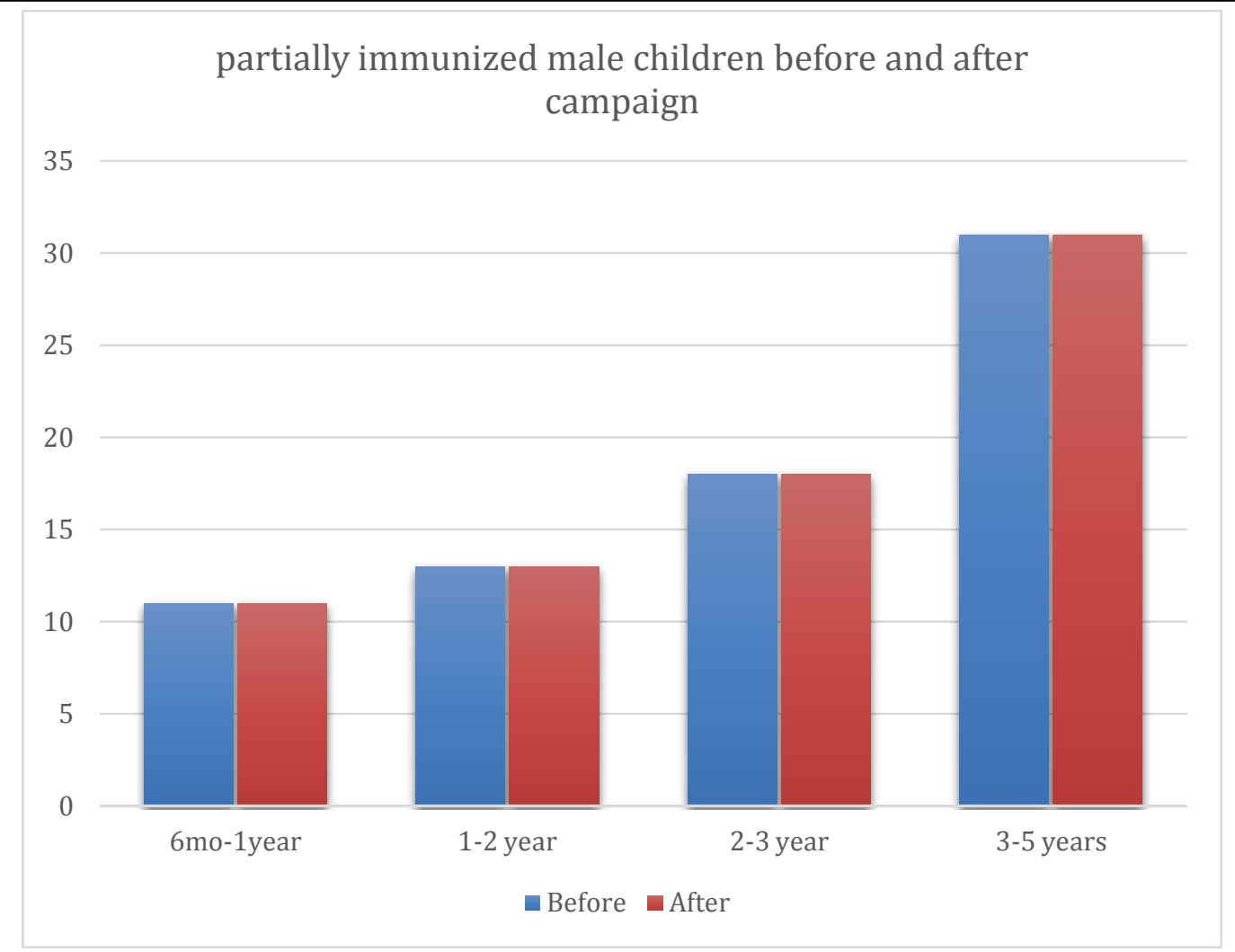

Immunization status based on religion

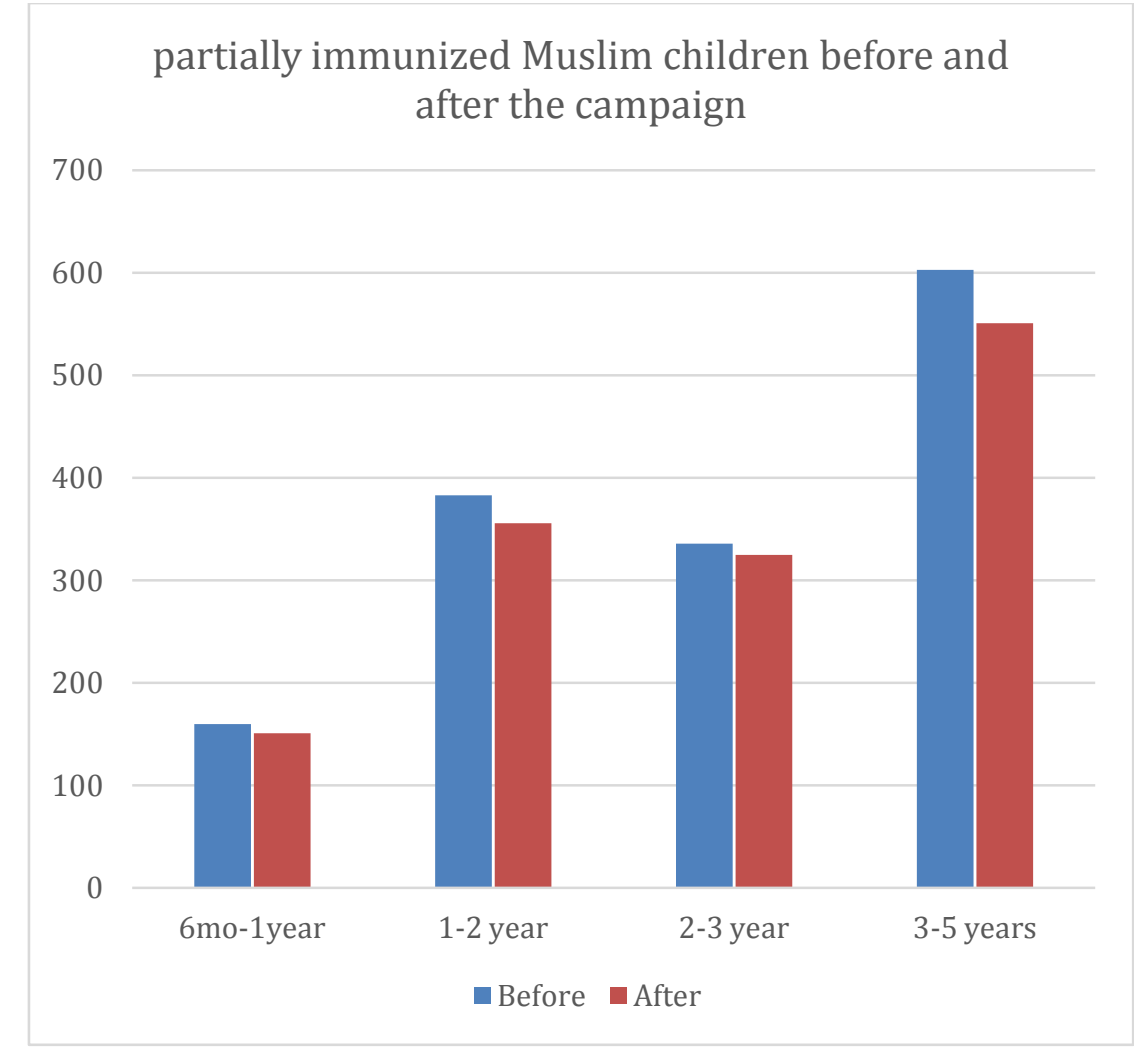




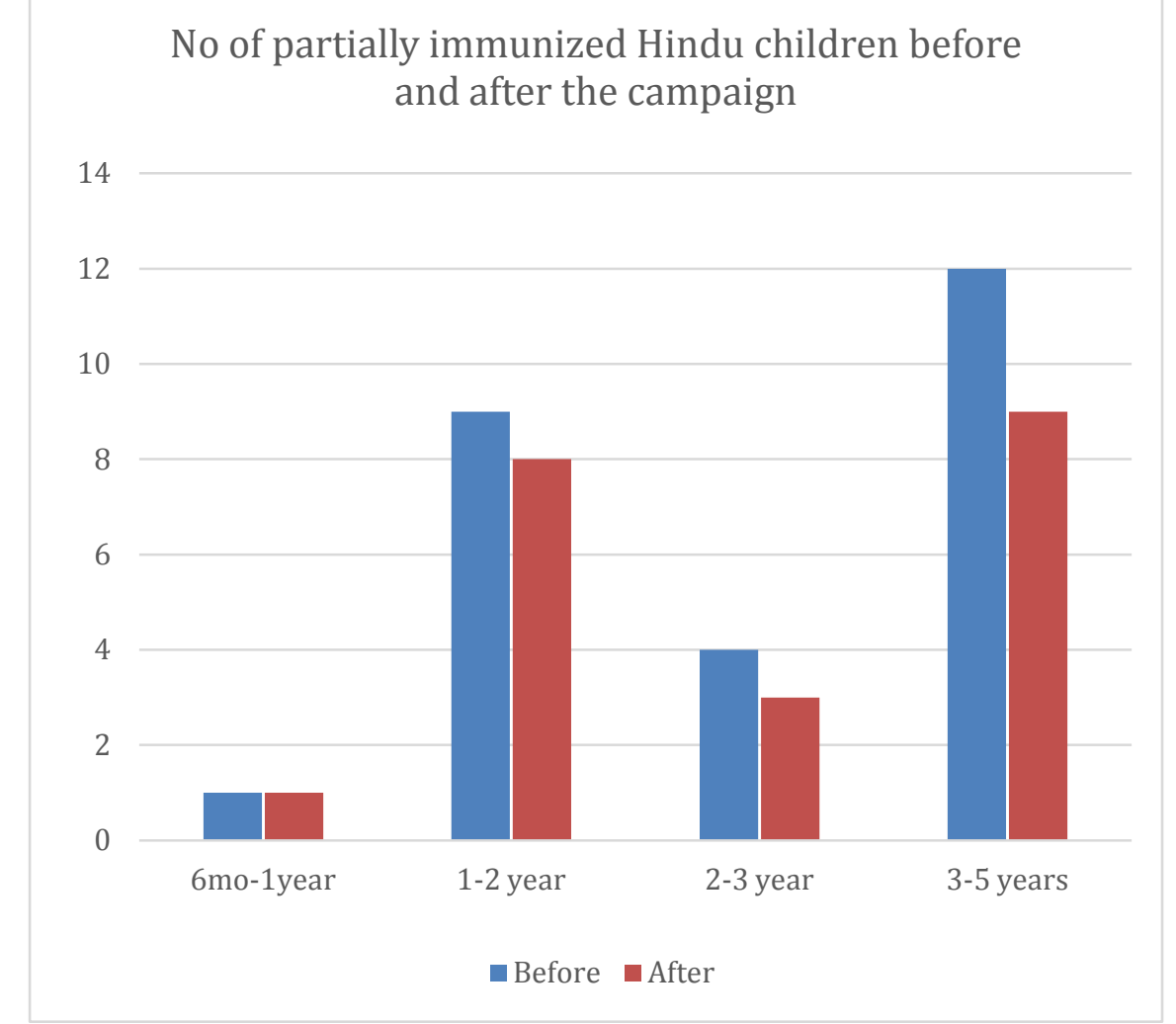

\section{Discussion}

Vaccination is a proven and one of the most cost effective child survival interventions $* 2$

Immunization averts an estimated 2 to 3 million deaths every year from diphtheria, tetanus, pertussis and measles; however, an additional 1.5 million deaths could be avoided if global vaccination coverage improves. Global vaccination coverage- the proportion of the world's children who received recommended vaccines-has stalled over the past few years.

Global vaccination coverage has stalled at $86 \%$ with no significant changes during the past year.*3

In the present analysis we found that the immunization coverage of under five children before the campaign $(\mathrm{n}-8341)$ is $80.02 \%$. (UI $0.19 \%$, PI $18.89 \%$ ).

Under 16 children (n-27690) immunization coverage $76.05 \%$ (UI $2.77 \%$ and PI $21.8 \%$ )

After the intensified immunization campaign 0-5, $9 \%$ became fully immunized, 7-16yrs $18.07 \%$ became fully immunized.

Unimmunized children- 0-5yrs $3.77 \%$ became partially immunized, 7-16 yrs $19 \%$ became partially immunized. Older children (7-16) are getting benefitted with school immunization schedules with 3 sessions $32.8 \%$ of unimmunized got Td vaccination.

\section{Conclusion}

Large majority of Unimmunized /partially immunized children remain unchanged as parents are reluctant to accept vaccines even after the intensified campaigns. Older children are getting benefitted with school immunization using $\mathrm{Td}$ vaccine. Type of Community played a significant role in resistance to immunization .Studies on factors causing resistance to immunization need to be done in detail, and newer strategies based on deeper understanding is needed to address this phenomenon of immunization resistance.

\section{References}

1. Hingson R. Obtaining optimal attendance at mass immunization programs. Health Serv Res 1974; 89:53-64.

2. Yokan C, D'Onofrio C. Application of health ed- ucation methods to achieve 
higher immunization rates. Public Health Rep 1978; 93:211-15.

3. Bussey AL, Holmes BS. Immunization levels: need they all decline? Lancet 1977^:970-1.

4. Sukhorukova NL, Korzhenkova MP, Sigaeva LA, et al. Data from different Moscow polyclinics on the utilization of vaccination against diphtheria, pertussis, tetanus, and measles in children of the first three years of life. (In Russian). Zh Mikrobiol Epidemiol Immunobiol 1982;8:112-16

5. Failure to vaccinate. (Editorial). Lancet 1983; 2:1343-4.

6. Friede AM, Waternaux C, Guyer B, et al. An epidemiologies! assessment of immunization programme participation in the Philippines. Int J Epidemiol 1985; 14:135-41.

7. Hand book on immunization for Medical officers's published by Department of Health and Family Welfare, Government of India 2008

8. World health organization (WHO) UNICEF, World Bank. State of the worlds vaccines and immunization,3rd edition. Geneva:WHO 2009.

9. Immunization coverage, Fact sheet. Reviewed January 2018 www.who.int/entity/mediacentre/factsheet s/fs378/en/ 